\title{
Impact of the grasping test on women's cardiovascular systems, and the possibility of replacing the orthostatic tolerance test with it
}

\author{
Karolina Zaluska ${ }^{1}$, Tomasz Sawicki ${ }^{1}$, Bartlomiej Kulesza ${ }^{2 *}$, Adam Nogalski ${ }^{2}$
}

\begin{abstract}
${ }^{1}$ The Student Scientific Society attached to the Chair and Department of Human Physiology, Medical University of Lublin, Poland ${ }^{2}$ Chair and Department of Trauma Surgery and Emergency Medicine, Medical University of Lublin, 16 Staszica St., 20-081 Lublin Poland
\end{abstract}

\section{ARTICLE INFO}

Received 12 November 2014

Accepted 03 December 2014

\section{Keywords:}

hypokinesia,

orthostatic intolerance,

Orthostatic Tolerance Test,

Grasping Test.

\begin{abstract}
The aim of this study was to test the impact of the Grasping Test (GT) on the female cardiovascular system and to ascertain the possibility of using this to replace the Orthostatic Tolerance Test (OT). In this study, 15 volunteer female students were examined, and their physiological parameters - their systolic (SBP) and diastolic blood pressures (DBP), and their heart rates (HR) - were compared. We found that the Orthostatic Tolerance Test (changing the position of the body from recumbent to upright) and the Grasping Test induced meaningful but similar changes in the functioning of the women's cardiovascular system. The results confirm that there were significant similarities between the cardiovascular system measurements as produced through the Orthostatic Tolerance Test and the Grasping Test. The possibility of introducing the procedure into clinical practice is a crucial factor for continuing our research in the wider population..
\end{abstract}

\section{INTRODUCTION}

Hypokinesia refers to decreased bodily movement. One of the two categories of movement disorders, hypokinesia is characterized by a partial or complete loss of muscle movement. Patients with hypokinetic disorders experience muscle rigidity and an inability to produce movement. It is also associated with mental health disorders and prolonged inactivity due to illness, amongst other diseases [14]. Hypokinesia effects all the bodily systems. It can be said,therefore, that it affects all the physiological processes of the human body. The long lasting bed-rest and limited physical activity which are forced by a number of diseases generate hypokinesia disorders, as the effect seriously alters physiological functions and biochemical reactions in human body and can be the cause of orthostatic intolerance $[2,4,18]$.

Orthostatic Intolerance (OI) is an effect that comes about when an adult stands up. In so doing, gravity pulls blood into the lower body and the blood pressure in the upper limbs, upper trunk and head decreases. This produces certain signs and symptoms that are relieved when the individual sits

\section{Corresponding author}

e-mail: kuleszabartek88@gmail.com

tel. +48 815321854 ,

fax. +48815329402 or lies down again. Normal human body reactions prevent blood accumulation in the lower body [3,12]. With Orthostatic Tolerance, while gravity pulls most of the body's blood down, the blood vessels contract, forcing blood up. Symptoms of OI are: pain, syncope, dizziness, weakness, vision and hearing impairments and sweating $[9,16,17]$. OI occurs in humans because standing upright is a fundamental stressor and requires rapid and effective circulator and neurologic compensations to maintain blood pressure, cerebral blood flow and consciousness $[4,15]$. People who suffer from OI lack the basis mechanisms to compensate for this deficit $[6,7]$. With regard to OI, the Orthostatic Tolerance Test is one of the favoured diagnostic tools. What is more, the Orthostatic Tolerance Test (OT) has been recently considered a robust independent predictor of cardiovascular events, including syncope (loss of consciousness) and the postural tachycardia syndrome $[5,8,10,13]$. All these complications can also influence the effectiveness and velocity of patients' rehabilitation [11].

The Grasping Test (GT) is a measurement of handgrip strength, and handgrip measurements have a variety of clinical applications. Among these are assessment of work ability post injuries or surgery and response to treatment, objective measurement of hand efficiency, and it can be 
important with regard to compensation after accidents or in influencing medical opinion with regard to disability. It is also possible that this test can measure cardiovascular (CV) fitness.

The purpose of our investigation was to ascertain the impact of the Grasping Test with regard to assessing women's cardiovascular system efficiency and the possibility of using this test to replace the standard Orthostatic Tolerance Test.

\section{MATERIALS AND METHODS}

In the present investigation, the $\mathrm{CV}$ responses to postural change and to the handgrip test were examined in 15 female student volunteers in the morning hours after at least 8-hours fasting. With regard to OT, assessment was done at first in the supine position, then upright and again in the supine position. As to GT, all measurements were performed in the horizontal position. In GT, all measurements were performed at first without any effort (in a relaxed state), then by grasping a dynamometer with the dominant hand with a strength equalling the quarter of the maximal value, and again in a relaxed state. Early, mid, and late $\mathrm{CV}$ responses in each stage of both tests were ascertained. Multiple readings of systolic (SBP) and diastolic blood pressure (DBP) and heart rate (HR) were recorded automatically with the use of cardio monitor Card(X)plore (Meditech, Budapest, Hungary). Statistical analysis of the data was performed with the use of computer software STATISTICA v. 10.0.

\section{RESULTS AND DISCUSSION}

Both the Orthostatic Tolerance Test (changing the position of the body from recumbent to upright - OT) and Grasping Test (GT) induced significant changes in the functioning of the test subjects' cardiovascular systems. Initially, increased systolic and diastolic blood pressure, as well as increased heart rate were observed. However, the changes were more significant when OT testing was conducted in the upright position than in the Grasping Test.

The presented tables and diagrams reveal the systolic blood pressure correlation in particular measurements taken while administering both tests. The Orthostatic Tolerance Test is marked by the letter S and the Grasping Test by the letter G. Statistical analysis shows correlations between the systolic blood pressure in both tests. Firstly, the following readings were compared: the first Orthostatic Tolerance Test and the first Grasping Test, the second OT and the second GT, the third upright posture OT and the third GT, as well as the fourth OT and GT. Significant similarity between the third Grasping Test and the third Orthostatic Tolerance Test was observed.

The systolic pressure readings in the second OT and in the fourth GT show significant similarity.

The decrease of the systolic blood pressure between the first and the last upright posture OT correlates with the dynamic increase of the systolic blood pressure between the first and the third readings in the GT. Similar relations in changes of the blood pressure appeared in both tests between the second and the fourth measurements, as well as between the third and the fourth measurements. Table 2 and Figure 1 present the diastolic blood pressure correlation in particular readings taken while administering both tests. The Orthostatic Tolerance Test is marked by the letter $\mathrm{S}$, and the Grasping Test by the letter G. Statistical analysis reveals the correlations between changes in diastolic blood pressure in both tests. Firstly, the following readings were compared: the first OT and the first GT, the second OT and the second GT, the third upright posture OT and the third GT, as well as the fourth OT and GT.

Table 1. The comparison of systolic blood pressure readings in both tests - the first, second, third and fourth measurements

\begin{tabular}{|c|c|c|c|c|}
\hline Variable & Average & $\begin{array}{c}\text { Standard } \\
\text { deviation }\end{array}$ & $T$ & $P$ \\
\hline S SBP1 & 119,00 & 10,84 & & \\
\hline G SBP1 & 115,80 & 13,29 & 0,983668 & $>00.5$ \\
\hline S SBP2 & 115,80 & 9,27 & & \\
\hline G SBP2 & 118,20 & 12,27 & $-0,806947$ & $>00.5$ \\
\hline S SBP3 & 117,93 & 13,17 & & \\
\hline G SBP3 & 118,20 & 11,76 & $-0,578730$ & $>00.5$ \\
\hline S SBP4 & 115,80 & 9,82 & & \\
\hline G SBP4 & 120,73 & 12,43 & $-1,52664$ & $>00.5$ \\
\hline
\end{tabular}

Table 2. The comparison of systolic and diastolic blood pressure readings in both tests - the first OT and the second GT measurements (diastolic) and the second OT and the fourth GT measurements (systolic)

\begin{tabular}{|c|c|c|c|c|}
\hline Variable & Average & $\begin{array}{c}\text { Standard } \\
\text { deviation }\end{array}$ & $T$ & $P$ \\
\hline S DBP2 & 76,0000 & 8,59402 & & \\
\hline G DBP1 & 69,8667 & 7,02919 & 2,7049 & $<00.5$ \\
\hline S SBP2 & 120,56 & 11,32 & & \\
\hline G SBP4 & 127,66 & 14,18 & $-3,4068$ & $<00.5$ \\
\hline
\end{tabular}

Values of diastolic blood pressure in the second OT in the upright position and in the first GT were significantly comparable. This result is presented in Table 2 and charted in Figure 1.

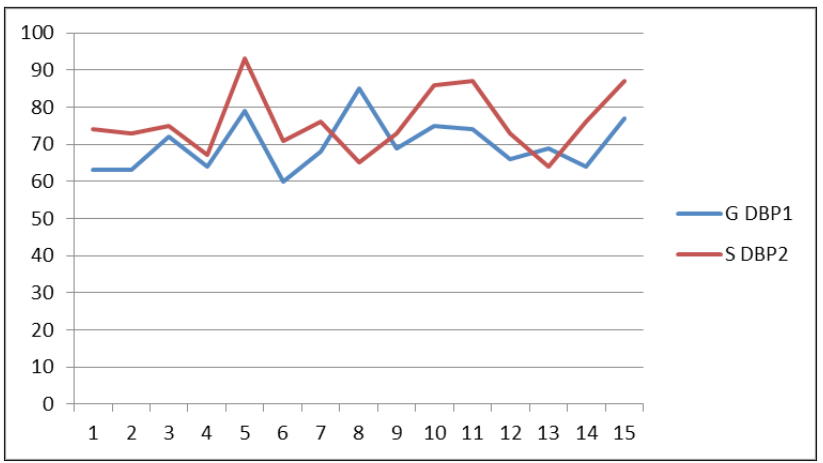

Figure 1. The comparison of diastolic blood pressure readings in particular participants - the second OT and the first GT measurements

The test subjects' heart rate values were similar in the Orthostatic Tolerance Test and in the Grasping Test. Table 3 presents the results. 
Table 3. The comparison of women's heart rate values in both tests - the OT and the corresponding GT measurements

\begin{tabular}{|c|c|c|c|c|}
\hline Variable & Average & $\begin{array}{c}\text { Standard } \\
\text { deviation }\end{array}$ & T & P \\
\hline S HR1 & 75,06 & 11,11927 & & \\
\hline G HR1 & 63,86 & 9,42540 & 3,787425 & $<00.5$ \\
\hline S HR2 & 79,26 & 9,691430 & & \\
\hline G HR2 & 65,06 & 8,387633 & 7,193085 & $<00.5$ \\
\hline S HR3 & 80,73 & 9,475281 & & \\
\hline G HR3 & 66,26 & 7,676185 & 6,171993 & $<00.5$ \\
\hline S HR4 & 76,53 & 7,744737 & & \\
\hline G HR4 & 67,46 & 7,799878 & 4,116086 & $<00.5$ \\
\hline
\end{tabular}

The Orthostatic Tolerance Test (changing the position of the body from recumbent to upright) and the Grasping Test induced significant changes in the functioning of the test subjects' cardiovascular systems. Initially, increased systolic and diastolic blood pressure, as well as increased heart rate were observed. However, the changes were more significantly evident when recording the OT postural test results than in all supine GT assessments.

The undertaken statistical analysis showed a significant correlation between changes in systolic and diastolic blood pressure values in both tests. The assessment of systolic blood pressure in the second measurement in the upright standing position of OT, correlated with the fourth measurement of the systolic blood pressure in GT. Also a strong similarity was seen between the second measurement of diastolic blood pressure in OT and the first measurement in GT $(p<0.05)$. Furthermore, the values of heart rate show a similar trend $(\mathrm{p}<0.05)$.

The research hypothesis assumes that the answer of the circulatory system to the Grasping Test is approximate to that to the observed Orthostatic Tolerance Test, and, therefore, they both may be used interchangeably. This also means that the range of tolerance in patients whose body position cannot be changed because of possible numerous other complications may be measured. The results confirm a significant correlation between a circulatory system reaction in Orthostatic Tolerance Testing and Grasping Testing. Of note, previous publications described only circulatory system changes in Orthostatic Tolerance Testing, and no data existed prior to our study concerning a comparison of both tests $[3,12,17]$.

\section{CONCLUSIONS}

The results of the conducted research give impetus towards introducing the Grasping Test for determining the cardiovascular reactivity in patients whose treatment require recumbence, and, hence, when it is not possible to conduct Orthostatic Tolerance Testing. Doing this would allow medical personnel to foresee possible complications in the process of rehabilitation, as well as to gain a greater understanding of the patient's susceptibility to treatment.
The results confirm the notion that there were significant similarities between the cardiovascular system measurements in Orthostatic Tolerance Testing and Grasping Testing. The possibility of introducing the procedure into clinical practice, is a crucial factor for continuing this research in the wider population.

\section{REFERENCES}

1. Bacir B. et al.: Omdlenia jako problem kardiologiczny. Przegląd Lekarski, 509-513, 53(6), 1996.

2. Bou-Holaigah I. et al.: The relationship between neurally mediated hypotension and the chronic fatigue syndrome. JAMA, 961, 274, 1995.

3. Calkins H., Rowe PC: Relationship Between Chronic Fatigue Syndrome and Neurally Mediated Hypotension. Cardiol. Rev., 125-134, 6, 1998.

4. Celej-Szuster J. et al.: Osteoporosis - risk factors, prophylaxis, diagnostic tests and pharmacotherapy. Current Issues in Pharmacy and Medical Sciences, 105-108, 26(1), 2013.

5. EI-Bedawi KM., Hainsworth R.: Combined head-up tilt and lower body suction: A test of orthostatic tolerance. Clinical Autonomic Research, 41-47, 4, 1994.

6. Golec L.: Hipograwia ortostatyczna. Polski Przeglad Medycyny Lotniczej, 41-47, 7, 2001.

7. Ismena Głowania: Hipotonia ortostatyczna u pacjentów w podeszłym wieku. Medycyna metaboliczna, 78-84, 4, 2000.

8. Koźluk E., et al.: Indukowany pionizacją częstoskurcz zatokowy -spojrzenie na czynnościowe zaburzenia rytmu. Kardiol. Dypl., 32-36, 8(1), 2009.

9. Lelonek Małgorzata: Nagła utrata świadomości- praktyczny przodownik. Terapia, 6-11, 19(3), 2011.

10. Low PA et al.: Postural tachycardia syndrome (POTS). Neurology, 19-25, 45, 1995.

11. Masuo K., et al.: Changes in freguency of orthostatic hypotension in elderly hypertensive patients under medications. Am. J. Hypertens., 263-268, 9, 1996.

12. Mellingsæter MR et al.: Gender differences in orthostatic tolerance in the elderly. Aging. Clin. Exp. Res., 659-65, 25(6), 2013.

13. Reznik et al.: Mortality from miocardil infarctio in different types of hospitals. Br. Med. J., 1121-1125, 294, 1987.

14. Rumuński S.: Częstość występowania i wyniki leczenia hipotonii ortostatycznej. Praca doktorska.

15. Schondorf R., Freeman R.: The importance of orthostatic intolerance in the chronic fatigue syndrome. Am. J. Med. Sci., 117-23, 317, 1999.

16. Stewart JM et al.: Patterns of orthostatic intolerance: the orthostatic tachycardia syndrome and adolescent chronic fatigue. J. Pediatr., 218-25, 135, 1999.

17. Stewart JM.: Common syndromes of orthostatic intolerance. Pediatrics., 968-980, 131(5), 2013.

18. Sviridkina NB et al.: Morphofunctional study of antiortostatic hipokinesia action in the case of focal ischemic brain cortex damage. Patol. Fiziol. Eksp. Ter., 22-6, 2, 2012. 